\title{
cis-Isotactic 1,4-Polypentadiene. NMR Solution Characterization and Crystal Structure of Polymers Prepared with Neodymium-Catalytic Systems
}

\author{
Barnasan Purevsuren, ${ }^{\dagger}$ Giuseppe Allegra, Stefano Valdo Meille, ${ }^{\dagger \dagger}$ Alessandra Farina, \\ Lido PORRI,* and Giovanni RICCI** \\ Dipartimento di Chimica del Politecnico di Milano, Via Mancinelli 7, 20131 Milano, Italia \\ * Dipartimento di Chimica Industriale e Ingegneria Chimica del Politecnico di Milano, \\ Piazza L. Da Vinci 32, 20133 Milano, Italia \\ **Istituto di Chimica delle Macromolecole del CNR, Via E. Bassini 15, 20133 Milano, Italia
}

(Received December 3, 1997)

\begin{abstract}
The synthesis of cis-1,4-isotactic polypentadiene with Neodymium (Nd)-catalytic systems yields polymers of higher stereoregularity than previously available and made possible the determination of the crystal structure of this polydiene. The lattice is orthorhombic with $a=9.49, b=6.07$, and $c$ (fiber axis) $=8.17 \AA$; space group P $2{ }_{1} 2{ }_{1}{ }_{1}$ implies the presence of two isochiral chains in the unit cell. The refinement of the crystal structure also establishes the details of the structure confirming the $\left(\mathrm{CS}^{+} \mathrm{TS}^{-}\right)_{2}$ chain conformation originally proposed on the basis of the fiber repeat.
\end{abstract}

KEY WORDS Crystal Structure / Fiber X-Ray Diffraction / cis-1,4-Isotactic Polypentadiene /

1,3-Pentadiene in its two isomeric forms $(E)$ and $(Z)$ may in principle be polymerized with $1,4-, 1,2-$, or $3,4-$ enchainment. In the last two cases the resulting systems have structural analogies with poly( $\alpha$-olefin)s and until now only the trans-1,2-syndiotactic ${ }^{1}$ and cis-1,2-syndiotactic $^{2}$ polymers have been synthesized. The main chain of the 1,4-polymers has two isomeric centers per monomeric unit, namely the double bond and the tertiary carbon atom (see Figure 1) and accordingly four different stereoregular polymers with such enchainment are conceivable. Three of these polymers have been actually prepared: namely the trans-1,4-isotactic, ${ }^{3}$ the cis-1,4isotactic, ${ }^{4-6}$ and the cis-1,4-syndiotactic $^{7-9}$ systems.

In the present paper we report on the synthesis, the nuclear magnetic resonance characterization and the crystal structure analysis of the cis-1,4-isotactic polypentadiene (PPCI) of high stereoregularity obtained with Neodymium (Nd)-catalytic systems.

\section{EXPERIMENTAL}

\section{Preparation of cis-1,4-Isotactic Polypentadiene} Catalyst Preparation. ${ }^{10} \quad 0.1 \mathrm{~g} \quad\left(1.7 \times 10^{-4} \mathrm{~mol}\right)$ of $\mathrm{Nd}\left(\mathrm{OCOC}_{7} \mathrm{H}_{15}\right)_{3}$ were dissolved in $6.6 \mathrm{~mL}$ of dry heptane in a $25 \mathrm{ml}$ dried flask. $\mathrm{AlEt}_{2} \mathrm{Cl}(0.065 \mathrm{ml}$, $5.1 \times 10^{-4} \mathrm{~mol}$ ) was added with stirring as $10 \%$ solution in heptane. The resulting suspension was stirred for $15 \mathrm{~min}$ at room temperature, and then $1.28 \mathrm{ml}(5.1 \times$ $\left.10^{-3} \mathrm{~mol}\right)$ of $\mathrm{Al}(\mathrm{iBu})_{3}$ were added at room temperature. The catalyst suspension was stirred for $40 \mathrm{~min}$ and then used in the polymerization runs.

Polymerization. (E)-1,3-Pentadiene $(2 \mathrm{ml})$ and heptane $(8 \mathrm{ml})$ were introduced in a $25 \mathrm{ml}$ dried flask. The solution so obtained was cooled to $-20^{\circ} \mathrm{C}$ and then $0.5 \mathrm{ml}$ of catalyst suspension $\left(1 \times 10^{-5} \mathrm{~mol}\right.$ of $\left.\mathrm{Nd}\right)$ were added with stirring. The polymerization was terminated with methanol after $23 \mathrm{~h}$, the polymer was coagulated and repeatedly washed with methanol, then dried in vacuum at room temperature. Polymer yield: $1.1 \mathrm{~g}$. Polymerizations were also carried out with similar procedures at $0^{\circ} \mathrm{C}$ and $+20^{\circ} \mathrm{C} .{ }^{13} \mathrm{C}$ and ${ }^{1} \mathrm{H}$ NMR spectra of PPCI were obtained in $\mathrm{CDCl}_{3}$ at room temperature using tetramethylsilane (TMS) as internal standard and a Bruker AM270 instrument.

Fibers of the polymer were obtained by stretching melt-crystallized thin films. Diffraction photographs were obtained using $\mathrm{Ni}$-filtered $\mathrm{Cu}-K_{\alpha}$ radiation with both cylindrical and flat (Kiessig) vacuum cameras. Typical sample-to-film distances were 56.7 and $65 \mathrm{~mm}$ respectively. Diffraction intensities were obtained from exposures differing typically by a factor of three, using both a flat-bed bidimensional microdensitometer (Officine Elettrotecniche di Tenno) and an Optronics 1000 film scanner. Closely comparable results were obtained. Bidimensional integration was performed using the program Guckmal ${ }^{11}$ and user defined integration areas, establishing actual scale factors between different films from common, non saturated reflections. Very weak reflection intensities were estimated by visual comparison with the scale established by numerical integration for the higher intensity reflections.

\section{RESULTS AND DISCUSSION}

The ${ }^{13} \mathrm{C}$ and ${ }^{1} \mathrm{H}$ NMR solution spectra of PPCI obtained at $-20^{\circ} \mathrm{C}$ together with peak attributions as indicated in the literature, ${ }^{12,13}$ are reported respectively in Figures 2 and 3. The cis content was about 95\%, the

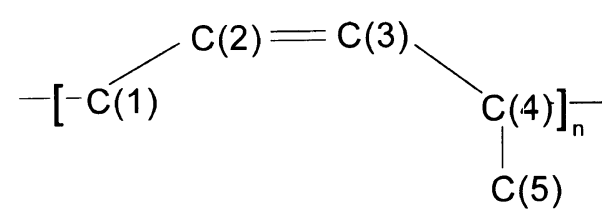

Figure 1. cis-1,4-Isotactic polypentadiene repeat unit.

\footnotetext{
${ }^{\dagger}$ Present address: Institute of Chemistry, Mongolian Academy of Sciences, Ulaanbaatar-51, Mongolia

${ }^{\dagger}$ To whom correspondence should be addressed.
} 


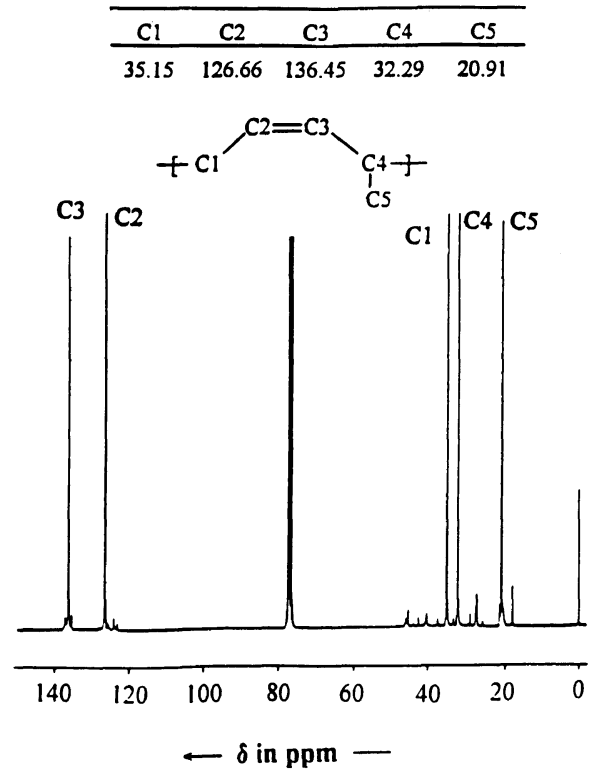

Figure 2. $67 \mathrm{MHz}{ }^{13} \mathrm{C}$ NMR spectra of cis-1,4-isotactic polypentadiene obtained with Nd-catalyst at $-20^{\circ} \mathrm{C}$.

$$
\begin{aligned}
& \begin{array}{|l|l|l|l|l|}
\hline \mathrm{CH}_{2}(1) & \mathrm{CH}(2) & \mathrm{CH}(3) & \mathrm{CH}(4) & \mathrm{CH}_{3}(5) \\
\hline 1.991 & 5.280 & 5.175 & 2.460 & 0.936 \\
\hline
\end{array}
\end{aligned}
$$

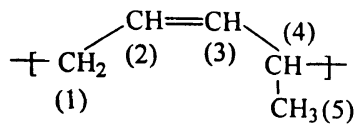

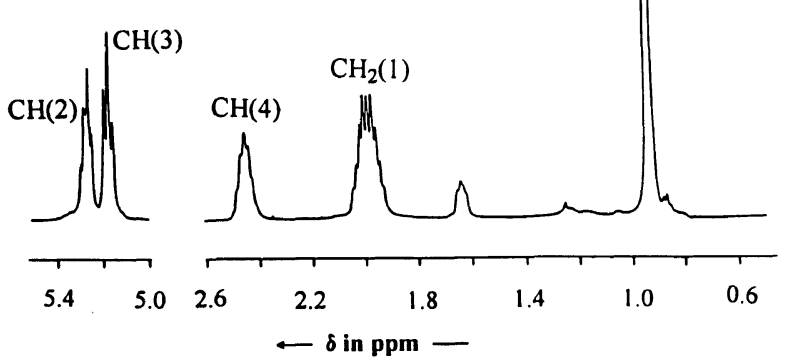

Figure 3. $500 \mathrm{MHz}{ }^{1} \mathrm{H}$ NMR spectrum of cis-1,4-isotactic polypentadiene obtained with Nd-catalyst at $-20^{\circ} \mathrm{C}\left(\mathrm{CDCl}_{3}\right.$, tetramethylsilane as internal standard, $+25^{\circ} \mathrm{C}$ ).

remaining units being 1,2 . The isotactic structure of the polypentadiene in this work is clearly indicated ${ }^{12}$ by the fact that the two methylene protons in the ${ }^{1} \mathrm{H}$ NMR spectrum (Figure 3) are isochronous while the same protons are anisochronous in the syndiotactic polymer.

As could be expected the polymerization of $(E)-1,3-$ pentadiene at low temperature $\left(-20^{\circ} \mathrm{C}\right)$ increased significantly both the cis-1,4-content and the molecular weights as compared to room temperature polymerization (see Table I). High crystallinity and good degrees of orientation were achieved with appropriate thermal treatments and the quality of fiber diffraction patterns was accordingly improved (Figure 4).

Fiber spectra could be indexed in a straightforward fashion, consistent with the presence of a predominant crystalline polymorph characterized by an orthorhombic lattice with $a=9.49, b=6.07$, and $c$ (fiber axis) $=8.17 \AA$. Additional crystalline phases could possibly coexist as minor impurities. With four monomer units in the unit
Table I. Influence of the polymerization temperature on the cis-1,4 content and the molecular weight of the polymer

\begin{tabular}{ccc}
\hline $\begin{array}{c}\text { Polymerization } \\
\text { temperature } /{ }^{\circ} \mathrm{C}\end{array}$ & $\begin{array}{c}c i s-1,4 \\
\text { Content } / \%\end{array}$ & $\frac{[\eta]}{\mathrm{dl} \mathrm{g}{ }^{-1}}$ \\
\hline 20 & 84.0 & 2.5 \\
0 & 88.5 & 3.6 \\
-20 & 95.0 & 5.9 \\
\hline
\end{tabular}

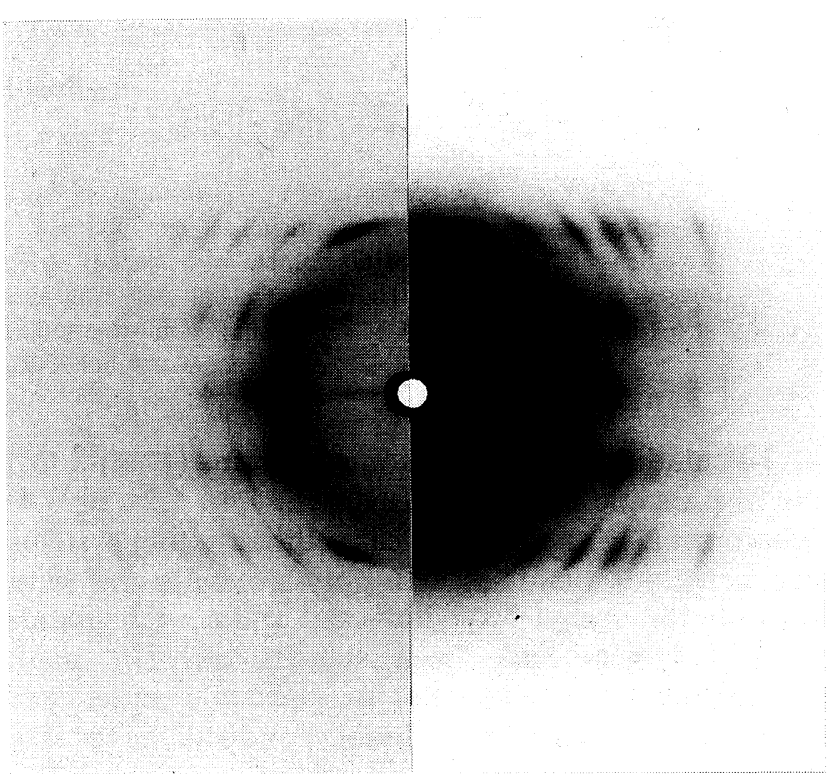

Figure 4. Fiber diffraction pattern of PPCI: the fiber axis, parallel to the crystallographic chain axis $c$, is vertical.

cell $(Z=4)$ a calculated density $\rho_{\text {calc }}$ of $0.961 \mathrm{~g} \mathrm{~cm}^{-3}$ results which is consistent with the experimental value. 21 diffraction intensities belonging respectively to the equator, to the first and to the second layer line could be measured to a resolution of approximately $1.9 \AA$ while 20 reflections were considered unobserved. The space group was assumed on the basis of the systematic absences and of the number of chains in the unit cell to be $\mathrm{P} 22_{1} 2_{1} 2_{1}$. This hypothesis was confirmed by the results of the refinement which was carried out using linked atom least squares $\left(\mathrm{LALS}^{14}\right)$ procedures. Fixed bond lengths and the starting values of the subsequently refined bond and torsion angles were established from the central unit of a pentamer on the basis of unconstrained MM2 $2^{15}$ calculations.

The relative intensities of equatorial reflections suggest locating the twofold helical isotactic chains on two symmetry related crystallographic binary screw axes parallel to the $c$ lattice vector (e.g., at $x=0.25, y=0$ and at $x=0.75, y=0.5$, respectively). The structure was solved varying the setting angle around and the translation along the chain axis for a rigid body chain model derived from the MM2 calculations and complying with the symmetry and periodicity requirements. The chain model, with hydrogen atoms at calculated positions, was then refined under geometrical constraints for the packing models most promising with respect to the crystallographic disagreement factor $R$ and to non-bonded contacts. The relevant geometrical data of the final 
Table II. Bond lengths adopted $(\AA)$ and refined values $\left({ }^{\circ}\right)$ of bond and torsion angles for PPCI

\begin{tabular}{|c|c|c|c|c|c|c|}
\hline \multicolumn{7}{|c|}{ Bond lengths $/ \AA$} \\
\hline$C(1)-C(2)$ & 1.512 & $C(2)-$ & (3) & 1.344 & $C(3)-C(4)$ & 1.512 \\
\hline $\mathrm{C}(4)-\mathrm{C}(5)$ & 1.538 & $C\left(1^{\prime}\right)$ & $C(4)$ & 1.538 & $\mathrm{C}-\mathrm{H}$ & 1.092 \\
\hline \multicolumn{2}{|c|}{ Bond angles $/^{\circ}$} & \multicolumn{5}{|c|}{ Torsion angles $/^{\circ}$} \\
\hline \multicolumn{2}{|c|}{$\mathrm{C}(1)-\mathrm{C}(2)-\mathrm{C}(3)$} & 127.2 & \multicolumn{3}{|c|}{$\mathrm{C}(1)-\mathrm{C}(2)-\mathrm{C}(3)-\mathrm{C}(4)$} & 0.9 \\
\hline \multicolumn{2}{|c|}{$C(2)-C(3)-C(4)$} & 126.7 & \multicolumn{3}{|c|}{$\mathrm{C}(2)-\mathrm{C}(3)-\mathrm{C}(4)-\mathrm{C}\left(1^{\prime}\right)$} & -124.8 \\
\hline \multicolumn{2}{|c|}{$C(3)-C(4)-C(5)$} & 109.0 & \multicolumn{3}{|c|}{$\mathrm{C}(2)-\mathrm{C}(3)-\mathrm{C}(4)-\mathrm{C}(5)$} & 112.8 \\
\hline \multicolumn{2}{|c|}{$\mathrm{C}\left(1^{\prime}\right)-\mathrm{C}(4)-\mathrm{C}(3)$} & 110.6 & \multicolumn{3}{|c|}{$\mathrm{C}(3)-\mathrm{C}(4)-\mathrm{C}\left(1^{\prime}\right)-\mathrm{C}\left(2^{\prime}\right)$} & -176.8 \\
\hline \multicolumn{2}{|c|}{$\mathrm{C}(4)-\mathrm{C}\left(1^{\prime}\right)-\mathrm{C}\left(2^{\prime}\right)$} & 109.9 & \multicolumn{3}{|c|}{$\mathrm{C}(4)-\mathrm{C}\left(1^{\prime}\right)-\mathrm{C}\left(2^{\prime}\right)-\mathrm{C}\left(3^{\prime}\right)$} & 118.8 \\
\hline
\end{tabular}

Table III. Fractional atomic coordinates of refined PPCI model

\begin{tabular}{cccc}
\hline Atom & $x$ & $y$ & $z$ \\
\hline $\mathrm{C}(1)$ & 0.2173 & -0.0991 & -0.1919 \\
$\mathrm{C}(2)$ & 0.1061 & -0.0092 & -0.3063 \\
$\mathrm{C}(3)$ & 0.112 & -0.0018 & -0.4706 \\
$\mathrm{C}(4)$ & 0.2293 & -0.0850 & -0.5784 \\
$\mathrm{C}(5)$ & 0.1761 & -0.2837 & -0.6776 \\
\hline
\end{tabular}

Table IV. Observed and calculated structure factors for PPCI

\begin{tabular}{|c|c|c|c|c|c|}
\hline$h k l$ & $F_{0}$ & $F_{\mathrm{c}}$ & $h k l$ & $F_{0}$ & $F_{\mathrm{c}}$ \\
\hline 110 & 70.1 & 65.9 & 221 & 7.0 & 13.4 \\
\hline 200 & 42.1 & 35.2 & $401^{\mathrm{UR}}$ & 4.2 & 1.0 \\
\hline 210 & 19.6 & 24.2 & {$\left[\begin{array}{l}411 \\
321\end{array}\right.$} & 7.0 & 7.4 \\
\hline 020 & 12.6 & 16.1 & $031^{\text {UR }}$ & 4.2 & 1.4 \\
\hline $120^{\mathrm{UR}}$ & 4.2 & 2.0 & $131^{\mathrm{U}}$ & 4.2 & 6.8 \\
\hline $310^{\mathrm{U}}$ & 4.2 & 4.7 & $501^{\mathrm{UR}}$ & 4.2 & 2.6 \\
\hline $220^{\mathrm{U}}$ & 4.2 & 5.0 & {$\left[\begin{array}{l}4211^{\mathrm{UR}} \\
231\end{array}\right.$} & 4.2 & 3.7 \\
\hline $400^{\mathrm{UR}}$ & 4.2 & 2.3 & 102 & 34.1 & 22.8 \\
\hline$\Gamma 410$ & 7.0 & 9.4 & $012^{\mathrm{UR}}$ & 4.2 & 0.3 \\
\hline L 320 & & & & & \\
\hline 130 & 6.1 & 6.0 & 112 & 15.0 & 8.4 \\
\hline$\left[\begin{array}{l}230^{\mathrm{UR}} \\
420\end{array}\right.$ & 4.2 & 2.8 & $202^{\mathrm{U}}$ & 4.2 & 5.4 \\
\hline 101 & 8.0 & 10.1 & 212 & 17.3 & 15.8 \\
\hline 011 & 7.0 & 11.4 & {$\left[\begin{array}{l}302 \\
022\end{array}\right.$} & 16.0 & 15.0 \\
\hline 111 & 33.7 & 24.1 & $122^{\mathrm{U}}$ & 4.2 & 5.7 \\
\hline 201 & 20.1 & 23.6 & 312 & 10.8 & 10.3 \\
\hline 211 & 23.4 & 24.9 & $222^{\mathrm{UR}}$ & 4.2 & 2.8 \\
\hline $301^{\mathrm{UR}}$ & 4.2 & 2.3 & $402^{\mathrm{UR}}$ & 4.2 & 1.0 \\
\hline 021 & 17.3 & 10.8 & {$\left[\begin{array}{l}412 \\
322\end{array}\right.$} & 14.5 & 10.6 \\
\hline 121 & 9.4 & 16.1 & $032^{\mathrm{UR}}$ & 4.2 & 1.8 \\
\hline $311^{\mathrm{UR}}$ & 4.2 & 3.4 & & & \\
\hline
\end{tabular}

${ }^{\mathrm{U}}$ Unobserved reflection participating in the refinement (a threshold value of one-half the lowest observed intensity is arbitrarely adopted). UR Unobserved reflection rejected from the refinement because the calculated value is below the chosen threshold value.

model, its fractional coordinates and the list of observed structure factors and calculated values for the refined structure are provided respectively in Tables II, III, and IV while two views of the crystal packing are given in Figure 5. The final disagreement factor $R$, determined on $F$ values including unobserved reflections, was 0.226 , while $R_{\mathrm{w}}$, with a Cruickshank weighting scheme was
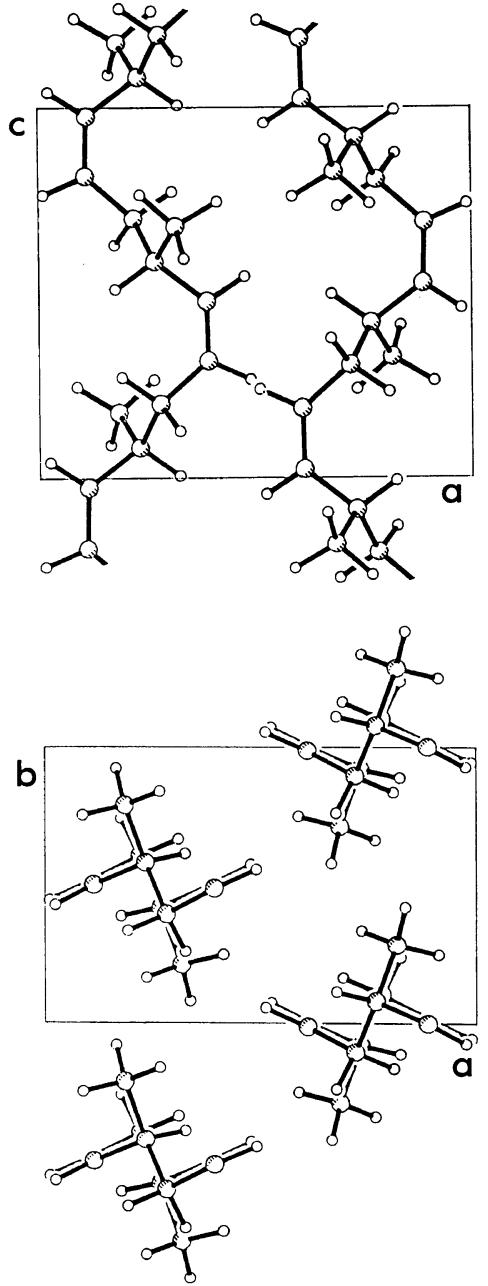

Figure 5. Projections of the packing of the PPCI molecules in the crystal respectively along the $b$ and $c$ crystallographic axes.

0.263 .

The refined isotropic temperature factor $\left(B=20 \AA^{-2}\right)$ corresponds to a root-mean square deviations of $c a .0 .5 \AA$ indicating that substantial disorder must exist within crystallites. It should be noted in addition that reflections are rather broad with typical FWHM (full widths at half-maximum) in some cases greater than $1^{\circ}(2 \theta)$ suggesting that crystallites are rather small, on the order of $70 \AA$. The large temperature factor may be due to various factors namely i) the fact that data were collected at $25^{\circ} \mathrm{C}$, i.e., relatively close to the melting point of $47^{\circ} \mathrm{C}$ determined by DSC for our polymer, ii) the small crystal size (which causes also diffraction peak broadening) makes atoms on the periphery of the crystal more mobile iii) the presence of conformational or configurational defects. We can speculate that factors ii) and iii) may be related to the mentioned presence of $c a$. 5\% units polymerized in 1, 2-enchainment, a fact which is bound to affect the crystallizability not only of the individual unit but also of its nearest neighbors.

Because of the substantial disorder a detailed discussion of the refined bond and torsion angles values should proceed very carefully. The $\left(\mathrm{CS}^{+} \mathrm{TS}^{-}\right)_{2}$ conformation originally proposed by two of us for $\mathrm{PPCI}^{4}$ and already determined for the related cis-1,4-isotactic poly(2-methyl-1,3-pentadiene) (P2MP) ${ }^{16,17}$ is fully confirmed. In the course of the refinement constraints applied 
to bond angles were approximately ten-fold as compared to those applied to dihedral angles (except for the double bond torsion angle). It is thus not surprising that deviations from the values determined on the basis of force-field calculations on isolated oligomers or from experimental studies of the related cis-1,4-isotactic poly(2-methyl-1,3-pentadiene) affect mainly the torsion angles. The values of the deviations are somewhat larger than expected, i.e., approximately $15^{\circ}$, for the $\mathrm{S}^{+}$and the $\mathrm{S}^{-}$conformations while they are negligible for the cis and the trans dihedral angles. This appears to be consistent with the fact that the rotational minima for single bonds adjacent to double bonds (syn conformers) are broader than for the $\mathrm{C}(4)-\mathrm{C}\left(1^{\prime}\right)$ bond between $s p^{3}$ hybridized carbons. Molecular mechanics calculations indicate that within $c a$. $0.5 \mathrm{kcal} \mathrm{mol}^{-1}$ deviations from the torsional minimum of $20^{\circ}$ or more are allowed in the first case but only of $12-15^{\circ}$ in the latter case.

The packing of the chains in the crystal deserves some comments: the $\mathrm{P} 2{ }_{1} 2{ }_{1} 2_{1}$ space group is chiral and the two chains in the unit cell are homochiral while having opposite directionalities. The chain arrangement is quite close to hexagonal: a common feature in chiral structures of helical molecules which is apparently promoted by kinetic factors. ${ }^{18}$ In the present instance the isotactic nature of the polymer implies that the asymmetric carbons in an individual chain must share the same chirality at least for long sequences. Therefore it appears likely that if nuclei develop from a single chain, as it is plausible in dilute solution, they tend to be chiral. Indeed in the related case of cis-iso-poly-2-methylpentadiene a chiral crystal structure is observed for the solution crystallized polymer, while from the melt racemate crystals develop in which chains of both chiralities coexist. ${ }^{16,17}$ The achiral structure in the case of P2MP appears to be the most stable one according to packing energy calculations. ${ }^{19}$ In the case of PPCI only a chiral crystal structure has been identified so far also from the melt suggesting that for this polymer the chiral structure may well be the more stable one, besides being kinetically favored. It is also worth noting that, although PPCI molecules are twofold helices and enantiomeric chains are readily distinguished due to the opposite configuration at $\mathrm{C}(4)$, the helical handedness of PPCI molecules is hard to define. This fact relates to the presence of a cis, a trans, and two opposite syn, i.e., compensating torsion angles within the repeat unit.

\section{CONCLUDING REMARKS}

The crystalline conformation obtained from fiber data corresponds to the two-fold helical conformation anticipated on the basis of the fiber periodicity in previous papers. It is closely related to the conformation found for both polymorphs of isotactic 1,4-cis-poly(2-methyl1,3-pentadiene). ${ }^{16,17}$ No experimental evidence exists at present in the case of PPCI for the three-fold helical conformer established as the preferred structure for isotactic 1,4-cis-poly(3-methyl-1,3-pentadiene). ${ }^{20}$

Acknowledgments. The authors thank the Italian "Ministero per l'Università e la Ricerca Scientifica" (MURST 40\%) and the "Consiglio Nazionale delle Ricerche-Progetto Strategico Tecnologie Chimiche Innovative" for funding.

\section{REFERENCES}

1. L. Porri, A. Di Corato, and G. Natta, Eur. Polym. J., 5, 1 (1969).

2. G. Ricci, S. Italia, and L. Porri, Macromolecules, 27, 868 (1994).

3. G. Natta, L. Porri, P. Corradini, G. Zanini, and F. Ciampelli, J. Polym. Sci., 51, 463 (1961).

4. G. Natta, L. Porri, G. Stoppa, G. Allegra, and F. Ciampelli, J. Polym. Sci., B, 1, 67 (1963).

5. G. Natta, L. Porri, A. Carbonaro, and G. Stoppa, Makromol. Chem., 77, 114 (1964).

6. F. Cabassi, S. Italia, G. Ricci, and L. Porri, in "Transition-Metal Catalyzed Polymerization," R. P. Quirk, Ed., Harwood Academics, New York, N.Y., 1988, pp 655-670.

7. L. Porri and A. Carbonaro, Makromol. Chem., 60, 236 (1963).

8. G. Natta, L. Porri, A. Carbonaro, F. Ciampelli, and G. Allegra, Makromol. Chem., 51, 229 (1962).

9. G. Ricci, S. Italia, C. Comitani, and L. Porri, Polym. Commun., 32, 513 (1991).

10. G. Ricci, S. Italia, F. Cabassi, and L. Porri, Polym. Commun., 28, 223 (1987).

11. J. E. Ladner, P. Machin, M. Elder, I. Clifton, and C. Nave, "Guckmal-An interactive program for X-ray fibre diffraction images," SERC-Daresbury Laboratory, 1987.

12. P. Aubert, J. Sledz, F. Schuè, and J. Prud'Homme, Eur. Polym. J., 16, 361 (1980).

13. P. Aubert, J. Sledz, F. Schuè, and C. Brevard, J. Polym. Sci., Polym. Chem. Ed., 19, 955 (1981).

14. S. Arnott and P. J. Campbell Smith, Acta Cryst., A34, 3 (1974).

15. N. L. Allinger, J. Am. Chem. Soc., 99, 8127 (1977).

16. S. Brückner, S. V. Meille, W. Porzio, and G. Ricci, Makromol. Chem., 189, 2145 (1988).

17. F. Cabassi, W. Porzio, G. Ricci, S. Brückner, S. V. Meille, and L. Porri, Makromol. Chem., 189, 2135 (1988).

18. S. V. Meille and G. Allegra, Macromolecules, 28, 7764 (1995).

19. D. R. Ferro, S. Brückner, S. V. Meille, and M. Ragazzi, Macromolecules, 24, 1156 (1991).

20. S. V. Meille, S. Capelli, G. Allegra, and G. Ricci, Makromol. Chem., Rapid Commun., 16, 329 (1995). 